Archived version from NCDOCKS Institutional Repository http://libres.uncg.edu/ir/asu/

\title{
Appalachl̈ăn
}

B O O N E, N O R T H C A R O L I N A

\section{The Development Of A Feedback Environment And Role Clarity Model Of Job Performance}

\author{
Authors: \\ Brian G. Whitaker, Jason J. Dahling \& Paul Levy
}

\begin{abstract}
:
Researchers have recently begun recognizing the impact of contextual factors on important organizational outcomes. This study, involving 170 subordinate-supervisor dyads, develops a model that demonstrates that subordinates who perceive a supportive feedback environment dis- play increased feedback seeking, higher role clarity, and higher performance ratings. Furthermore, the results show that effort costs moderated the relationship between the coworker feedback environment and feedback seeking from coworkers. Implications are discussed
\end{abstract}

Brian G. Whitaker, Jason J. Dahling \& Paul Levy (2007) "The Development Of A Feedback Environment And Role Clarity Model Of Job Performance." Journal of Management \#33, pp. 570-591 Version of Record Available At www.sagepub.com (DOI: 10.1177/0149206306297581) 


\section{Introduction}

Many researchers have demonstrated that proactive feedback seeking, the efforts made by employees to reduce uncertainty surrounding the acceptability of their performance, is both an important individual and organizational resource (Ashford, 1986; Ashford \& Cummings, 1983). In particular, research has focused on what Ashford and Cummings (1983) termed inquiry, the active request for feedback. This form of feedback seeking has shown clear benefits for both the individual and the organization (Hackman \& Oldham, 1976; Ilgen, Fisher, \& Taylor, 1979; Karan \& Kopelman, 1986), and much research has accordingly focused on identifying the determinants of feedback-seeking behavior (Levy, Albright, Cawley, \& Williams, 1995; Steelman, Levy, \& Snell, 2004; Williams, Miller, Steelman, \& Levy, 1999). 
Researchers have also tied feedback seeking to important organizational outcomes, such as job satisfaction, employee learning, and motivation (Hackman \& Oldham, 1976; Mignerey, Rubin, \& Gorden, 1995; Morrison, 1993; Murphy \& Cleveland, 1995; Wanberg \& Kammeyer-Mueller, 2000).

Because of the demonstrated importance of feedback-seeking behavior to organizations, researchers have recently made several calls to clarify poorly understood relationships in the feedback-seeking literature. First, several researchers have noted that the contextual antecedents of feedback-seeking behavior are relatively under-researched (e.g., Ashford, Blatt, \& Vandewalle, 2003; Levy \& Williams, 2004; Murphy \& Cleveland, 1995; Steelman et al., 2004). Specifically, recent work has emphasized that employees distinguish between different sources of feedback, such as supervisors and coworkers (Morrison \& Vancouver, 2000), and that contextual influences on feedback-seeking behavior may differ across these sources (e.g., Steelman et al., 2004).

Among the contextual antecedents that have been examined in past research are perceived effort costs (Ashford \& Cummings, 1983) and the feedback environment (Steelman et al., 2004). Effort costs reflect the perceived amount of effort that employees feel they must expend when seeking feedback. Similarly, the feedback environment measures the extent to which characteristics of the workplace encourage the use of inquiry. Research indicates that perceived effort costs in the workplace reduce feedback-seeking behavior (Ashford, 1986; Ashford \& Cummings, 1983) and that a supportive feedback environment increases feedback-seeking behavior (Steelman et al., 2004). Importantly, the feedback environment is measured across two dimensions, the supportiveness of the supervisor feedback environment and the coworker feedback environment. In contrast, little attention has been paid to differing effort cost perceptions across different feedback sources. Accordingly, the first goal of this study is to examine the extent to which feedback-seeking behavior across multiple sources is influenced by these important contextual antecedents.

A second recent call in the literature involves clarifying the relationship between feedback-seeking behavior and job performance. Ashford et al.'s (2003) recent review demonstrated that feedback yields a number of desirable outcomes for individuals, such as information about job tasks that should facilitate performance. Indeed, they stated that one of the more prevalent reasons for individuals to seek feedback was the instrumental motive, which encourages employees' feedback-seeking behavior based on the perceived informational value of feedback. From this perspective, feedback assists in behavioral selfregulation, and feedback seeking should result in improved performance over time.

However, despite the body of research investigating the outcomes of feedback seeking, the research that has specifically investigated the relationship between feedback seeking and job performance remains inconsistent (Ang, Cummings, Straub, \& Earley, 1993; Ashford \& Black, 1996; Morrison, 1993). To address this gap in the literature, researchers have recently called for studies examining the mechanisms through which feedback-seeking behavior may lead to increases in job performance (Ashford et al., 2003; Morrison, 2002; VandeWalle, 2003). Consistent with authors who have argued that the link between feedback-seeking behavior and job performance is complex and likely indirect (Ashford et al., 2003; Morrison, 2002; VandeWalle, 2003), we maintain that the ambiguous relationship between feedback seeking and job performance can be best understood from the perspective of role clarity 
(Kahn, Wolfe, Quinn, Snoek, \& Rosenthal, 1964; Sawyer, 1992) acting as a mediator between these two variables.

According to Banton (1965), a "role" is defined as a set of expectations or norms applied to the incumbent by others in the organization, and employees with high role clarity therefore possess a clearer understanding of their requirements. Interestingly, some evidence indicates that feedback-seeking behavior may increase role clarity, and subsequently job performance. For example, Kahn et al. (1964) introduced the role episode model, which demonstrated that the incumbent reciprocally interacts with others in the environment via a feedback loop in order to gain the requisite knowledge to successfully carry out organizational responsibilities. Similarly, Taylor, Fisher, and Ilgen (1984) stated that feedback seeking for instrumental reasons clarifies the set of responsibilities, duties, and performance levels stipulated by the organization, thus leading to higher levels of job performance by reducing uncertainty about what feedback information is truly relevant to performance. Whereas this body of research highlights the importance of role clarity for improving task performance, an emerging literature also suggests that role clarity may be important to facilitating contextual performance as well (Bolino \& Turnley, 2005; Podsakoff, MacKenzie, \& Bommer, 1996; Podsakoff, MacKenzie, Paine, \& Bachrach, 2000; Salamon \& Deutsch, 2006). Thus, a second objective of this study is to help explain the relationship between feedback-seeking behavior and both task and contextual performance by considering the mediating position of role clarity.

In summary, the purpose of this study is to develop and empirically test models of feedbackseeking behavior from supervisors and from coworkers with several goals in mind. First, we explore how contextual elements of the workplace, such as the feedback environment and perceptions of effort costs, direct employees' attention toward current performance and performance-related feedback, thus making the value of feedback-seeking behavior salient. Second, we investigate role clarity as a mediator of the link between feedback-seeking behavior and job performance. Specifically, on the basis of recent research indicating that job performance is a multidimensional construct (e.g., Borman \& Motowidlo, 1993; Rotundo \& Sackett, 2002), we examine the mediating effects of role clarity on both task and contextual performance.

\section{The Feedback Environment}

Whereas the traditional definition of feedback largely reflects the notion that feedback is a process only between a feedback sender and a recipient (Ilgen et al., 1979; Morrison \& Bies, 1991), recent literature has demonstrated the influence of the context on feedbackseeking behavior (Levy, et al., 1995; Levy \& Williams, 1998; Williams et al., 1999). For example, the Feedback Environment Scale (FES; Steelman et al., 2004) is a measure that assesses the extent to which characteristics of the workplace encourage the use of active inquiry. This scale measures two distinct but related dimensions, one involving feedbackrelated interactions with supervisors and the other involving feedback-related interactions with coworkers. The FES therefore provides a measurement of the employee's perceptions of the overall supportiveness for feedback in the workplace. 
Moreover, unlike past attempts to measure the feedback context purely in terms of the provision of job performance information (e.g., Herold \& Parsons, 1985), the FES measures both the supervisor and coworker feedback environments in terms of seven subfacets, namely, feedback quality, source credibility, consideration in feedback delivery, provision of favorable feedback, provision of unfavorable feedback, source availability, and promotion of feedback seeking. Higher levels of all seven dimensions contribute to an increasingly supportive feedback environment. Accordingly, past research has demonstrated that the facets of the feedback environment relate positively to inquiry and to ratings of the quality of feedback that is subsequently received (Steelman et al., 2004; Steelman \& Rutkowski, 2004). Consistent with past research, we therefore hypothesize the following:

Hypothesis 1a: Perceptions of a supportive supervisor feedback environment will relate positively to feedback seeking (i.e., inquiry) from the supervisor.

Hypothesis $1 b$ : Perceptions of a supportive coworker feedback environment will relate positively to feedback seeking (i.e., inquiry) from the coworker.

\section{Effort Costs}

Although supportive supervisors and coworkers may create an environment conducive to feedback seeking, as noted by Renn and Fedor (2001), unless employees are willing and motivated to seek feedback, it is unlikely that they will do so. Ashford and Cummings (1983) proposed that a key determinant of feedback-seeking behavior is the perception of costs associated with feedback seeking. Self-presentation costs and ego costs have been shown to affect the extent to which one actively seeks feedback (Ashford, 1986, 1988; Fedor, Rensvold, \& Adams, 1992). However, little research has been devoted to exploring the impact of effort costs on feedback seeking. Effort costs are those that reflect the amount of effort that one must expend when seeking feedback (Ashford \& Cummings, 1983), and they are an important determinant of feedback seeking. For example, the work of VandeWalle and colleagues (Ashford, et al., 2003; Tuckey, Brewer, \& Williamson, 2002; VandeWalle, 2003; VandeWalle, Ganesan, Challagalla, \& Brown, 2000) suggests that goal orientation influences effort cost perceptions, which contributes to feedback-seeking tendencies. Specifically, learning-goal-oriented individuals focus more on the expected value of feedback seeking and less on the perception of costs, whereas performance-goal-oriented individuals tend to be discouraged by cost perceptions (VandeWalle \& Cummings, 1997).

Although this body of work has helped to illustrate how individual differences influence effort perceptions, little research has focused on the influence of context, such as the feedback environment. Ashford (1986) found a negative relationship between perceptions of effort cost and frequency of feedback behavior, but her measures of effort costs and feedback seeking did not distinguish between feedback source (i.e., the supervisor and the coworker). Because the feedback environment distinguishes between these separate sources (Steelman et al., 2004) and Morrision and Vancouver (2000) emphasized that employees seek feedback from different sources, we argue that perceptions of effort costs should also be examined separately. 
More important, we see a distinction between the feedback environment and effort costs. Although the feedback environment provides a great deal of information about employees' perceptions of the quality and type of feedback provided, as well as the availability and supportiveness of sources, it does not speak to other organizational circumstances that could make access to that available feedback difficult. For example, a supervisor could provide extremely useful feedback, encourage feedback seeking, and remain available to provide it, yet he or she could be so busy with job demands that subordinates need to schedule meetings well in advance and wait for feedback. In this situation, subordinates might report that the feedback environment is very supportive yet also perceive that effort costs associated with accessing the feedback are high. Effort costs are therefore another important contextual antecedent to feedback-seeking behavior.

Thus, the feedback environment does not necessarily reflect the amount of effort that employees must expend to access feedback. We therefore expect that feedback seeking in a supportive environment may be hindered if effort costs are high or facilitated if effort costs are perceived as low.

Hypothesis 2a: Effort costs will moderate the relationship between the supervisor feedback environment and feedback seeking from the supervisor.

Hypothesis $2 b$ : Effort costs will moderate the relationship between the coworker feedback environment and feedback seeking from coworkers.

\section{Feedback-Seeking Behavior, Role Clarity, and Job Performance}

Although feedback in general is largely thought to have a positive effect on task performance (Ilgen et al., 1979), Kluger and DeNisi's (1996) meta-analysis has demonstrated that the effects of feedback-based interventions vary considerably. Similarly, the findings of those studies that have been carried out investigating the relationship between feedback seeking and task performance are somewhat equivocal, with some finding effects (Morrison, 1993) and others finding no evidence for this link (Ang et al., 1993; Ashford \& Black, 1996).

We see two potential reasons for these inconsistent findings. First, these studies examined only the direct links between feedback seeking and performance, thus neglecting to investigate potential mediating variables that could clarify this relationship. For example, Morrison's (2002) model of employee information seeking suggests that feedback seeking should lead to immediate decreases in uncertainty with accompanying increases in job knowledge. According to this model, the accumulated effects of reduced uncertainty should lead to positive work attitudes and higher performance. Similarly, Taylor et al. (1984) suggested that clear standards were an important intermediary between feedback and changes in performance. From this perspective, an employee with poorly understood behavioral standards could disregard important feedback because he or she does not recognize that it is relevant and useful, resulting in no improvements in performance.

Second, those studies that have examined the feedback seeking-task performance link have not differentiated between feedback seeking from different sources. For example, Renn and Fedor's (2001) measure of feedback seeking was composed of two items, one assessing 
feedback seeking from the supervisor and the other from coworkers. Similarly, Ashford (1986) also used a conglomerate measure. Failing to distinguish between the sources for feedback seeking (Morrison \& Vancouver, 2000) may attenuate the link between feedback seeking and task performance. For example, it is feasible that an employee could be uncomfortable seeking feedback from coworkers yet seeks sufficient feedback from a supervisor to ensure adequate role clarity and job performance.

Accordingly, the present study suggests that the uncertainty-reducing effects of role clarity should mediate the links between feedback seeking from each source (supervisor and coworkers) and task performance. Several existing studies support this perspective. In settings that pro- vide employees with information pertaining to work performance and processes, Renn and Fedor (2001) found that goal setting mediated the feedback seeking-job performance link. Moreover, Williams and Johnson (2000) found that the use of feedback monitoring, the observation of the environment for useful information (Ashford \& Cummings, 1983), was related to greater agreement between self-ratings and supervisor ratings of performance. These findings suggest that feedback seeking may bolster an employee's understanding of the expectations of his or her job as well as his or her normative performance.

Although no one has investigated role clarity as a mediator of the feedback seeking-task performance link, researchers have demonstrated relationships between feedback-seeking behavior and role clarity (Ashford \& Cummings, 1985; Callister, Kramer, \& Turban, 1999; Wanberg \& Kammeyer-Mueller, 2000) and between role clarity and task performance (Fried, Ben-David, Tiegs, Avital, \& Yeverechyahu, 1998; McEnrue, 1984; Nhundu, 1992). However, despite literature suggesting that (a) feedback seeking is related to role clarity, (b) role clarity is related to task performance, and (c) feedback seeking and task performance may be linked through some mediating mechanism, the intervening influence of role clarity on the relationship between feedback seeking and task performance has yet to be investigated.

To this end, we hypothesize the following:

Hypothesis 3a: The relationship between feedback seeking from the supervisor and task performance will be fully mediated by role clarity.

Hypothesis $3 b$ : The relationship between feedback seeking from coworkers and task performance will be fully mediated by role clarity.

Moreover, enhanced role clarity achieved as a result of feedback-seeking behavior should also increase the frequency of organizational citizenship behaviors (OCBs) or contextual performance. Recently, researchers have begun to note the costs associated with performing OCBs, including role overload, work-family conflict, and job stress (Bolino \& Turnley, 2005; Salamon \& Deutsch, 2006). Given increasing expectations for employees to meet high expectations for both task and contextual performance, employees face a difficult challenge in managing these disparate demands (Bond, Galinsky, \& Swanberg, 1997). However, we expect that employees with enhanced role clarity should know the standards that they are expected to meet, which helps them determine when and how to perform OCBs that contribute to performance ratings without unexpected, negative outcomes. In other words, high role clarity could facilitate contextual performance by clarifying the extrarole behaviors that are valued by the organization and by giving employees a realistic sense of when OCBs can be performed without detracting from task 


\section{Figure 1}

\section{Final Path Model for the Supervisor Feedback Environment With Standardized Path Coefficients}

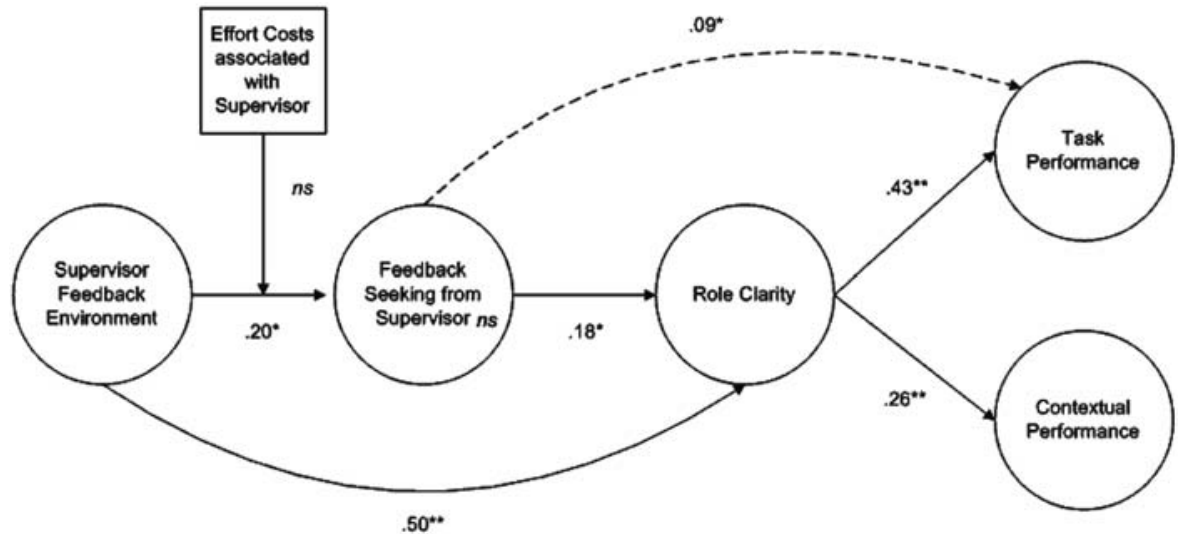

Note: $\chi^{2}(96, N=168)=158.41, p<.01$; Comparative Fit Index $=.95 ;$ root mean square error of approximation $=$ .08 ; standardized root mean square residual $=.07$.

$* p<.05$

performance. Recent meta-analyses demonstrating a positive relationship between role clarity and OCBs support this relationship (Podsakoff et al., 1996; Podsakoff et al., 2000). Thus, although this mediated relationship has not been explored in past research, we expect that role clarity that develops as a result of feedback-seeking behavior should facilitate contextual performance. Thus, we hypothesize the following:

Hypothesis $4 a$ : The relationship between feedback seeking from the supervisor and contextual performance will be fully mediated by role clarity.

Hypothesis $4 b$ : The relationship between feedback seeking from coworkers and contextual performance will be fully mediated by role clarity.

To summarize, the present study integrates current theoretical and empirical knowledge to investigate the effects of the feedback context on feedback-seeking behavior and of feedback-seeking behavior on job performance. Specifically, we have proposed distinct supervisor and coworker models on the basis of the literature that suggests that the feedback environments are distinct (Steelman et al., 2004), that feedback is sought from different sources (Morrison \& Vancouver, 2000), and that perceptions of effort costs may differ between sources. Both the supervisor model (Figure 1) and the coworker model (Figure 2), although assessed separately, illustrate that contextual antecedents, such as the feedback environment and perceived effort costs, influence feedback-seeking behavior. Furthermore, they indicate that feedback-seeking behavior will be positively related to task performance and contextual performance through the mediating effects of increased role clarity. 


\section{Figure 2}

Final Path Model for the Coworker Feedback Environment With Standardized Path Coefficients

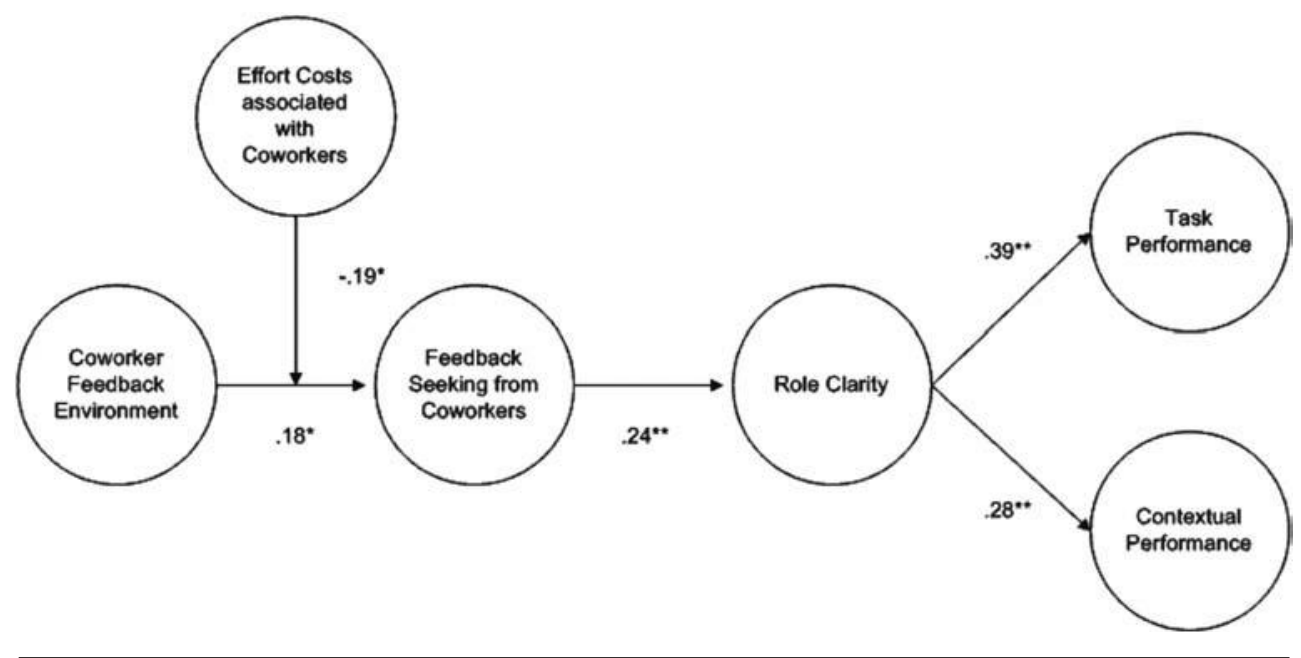

$\chi^{2}(99, N=170)=191.98, p<.01 ;$ Comparative Fit Index $=.95 ;$ root mean square error of approximation $=.07 ;$ standardized root mean square residual $=.08$.

$* p<.05$

$* * p<.01$

\section{Method}

\section{Participants}

Participants were 252 undergraduate students from a large mid-western university working at least 20 hours per week. Participants' supervisors were contacted via mail and surveyed regarding the performance of their subordinate. Subordinates whose supervisors did not return surveys were excluded from further analysis. One hundred seventy supervisors returned the survey, yielding a response rate of $67.4 \%$.

The mean age of the subordinates was 22.8 with an average tenure of approximately 27 months, working an average of 26.5 hours per week. The subordinate sample was $73.5 \%$ female, and $84.7 \%$ were Caucasian; $11.8 \%$ were African American; and 3.5\% were categorized as either Asian, Hispanic, Native American, or Other.

The average age of the supervisors was 39.14 years, with an average of 5.92 years of management tenure and an average of 22.6 months supervising the target employee. The super- visor sample was $60.6 \%$ female, and $82.9 \%$ were Caucasian; $6.8 \%$ were African American; and 6.1\% were categorized as either Asian, Hispanic, Native American, or Other. 


\section{Procedures}

Subordinate participants were compensated with extra credit for their involvement. Subordinates completed measures designed to assess their perceptions of the feedback environment in the workplace, the extent to which they seek feedback, their role clarity, and effort costs in obtaining feedback. Upon survey completion, subordinates completed a consent form allowing their supervisors to be contacted regarding their work performance. Each subordinate was then instructed to give a survey to his or her supervisor. The supervisor survey assessed employee task and contextual performance, as well as the supervisor's demographic information. Supervisors then mailed the completed surveys back to the researchers.

\section{Measures}

Subordinate measures. The FES was developed by Steelman et al. (2004) as a means of assessing employee perceptions of the supervisor and coworker feedback environments. Each feedback dimension and the seven facets composing each dimension were assessed with 7-point Likert-type scales ranging from strongly agree to strongly disagree. The aim of the present study was to examine the relationship of the general supervisor and coworker feedback environments to outcomes, thus analyses were carried out on the aggregate of the Supervisor $(\alpha=.94)$ and Coworker scales $(\alpha=.95)$ as has been done in other studies (e.g., Norris-Watts \& Levy, 2004; Rosen et al., 2006). A sample item from the Supervisor FES is "My supervisor generally encourages me to ask for feedback whenever I am uncertain about my job performance." A sample item of the Coworker FES is "My coworkers are often annoyed when I directly ask them for performance feedback (reverse-coded)."

Participants were also asked to respond to Williams and Johnson's (2000) six-item feedback-seeking measure ( $\alpha=.78$ ) designed to tap the frequency with which they directly seek feedback (i.e., inquiry) from their supervisors (three items) and their coworkers (three items). Sample items include "How often do you ask your supervisor for information about what is required of you to function successfully on the job?" and "How often do you ask your coworkers how well you are doing performing on the job?" This scale is measured with a 6point scale ranging from 1 (never) to 6 (always).

We used Sawyer's (1992) 10-item measure of role clarity to assess the degree of clarity with which employees understood their position $(\alpha=.91)$, which was rated on a 6-point scale $(1=$ very uncertain, $6=$ very certain $)$. The scale measures two facets, clarity of roles and clarity of processes.

Two items developed by Ashford (1986) were used as measures of perceived effort costs from supervisors and perceived effort costs from coworkers, respectively. The items, which read "How much effort does it take for you to get useful feedback from the following sources?" are asked in respect to the supervisor and coworkers. The item referring to effort costs associated with the supervisor was used as a one-item scale assessing effort costs from the supervisor, whereas the item referring to effort costs from coworkers served as a 
one-item scale tapping these perceptions from coworkers. Responses to these items are made on a 4-point Likert-type scale $(1=$ quite a lot, $2=$ some, $3=$ very little, $4=$ not at all $)$.

Supervisor measures. Supervisors were asked to complete questionnaires regarding various aspects of subordinate performance. Task performance data were collected using Williams and Anderson's (1991) seven-item measure of in-role behavior $(\alpha=.84)$. Sample items from this scale include "Adequately completes assigned duties" and "Meets formal performance requirements of the job." The Organizational Citizenship Behavior-Individual (OCBI) measure (seven items) and the Organizational Citizenship Behavior-Organizational (OCBO) measure (six items) were used to tap OCBIs and OCBOs, respectively (Williams \& Anderson, 1991). OCBIs $(\alpha=.88)$ tap behaviors benefiting specific individuals in the organization (i.e., "Helps others who have been absent"), whereas OCBOs $(\alpha=.75)$ tap those behaviors benefiting the organization as a whole (i.e., "Conserves and protects organizational property").

\section{Results}

The means, standard deviations, and coefficient alphas for the raw score variables are presented in Table 1, along with the latent variable correlations. Structural equation modeling using maximum likelihood estimation was employed for the purposes of testing the complete hypothesized models for the individual Supervisor and Coworker feedback environments. For both models, we followed the recommendations of Williams and Anderson (1994) and Hall, Snell, and Foust (1999) by creating parcels that share a secondary factor to serve as indicators of the latent variables. For the Supervisor Feedback Environment (SFE) model, seven parcels were created reflecting source credibility, feedback quality, feedback delivery, feedback favorability, unfavorable feedback, source availability, and the promotion of feed- back seeking. Two parcels were formed for role clarity representing goal and process clarity. Two parcels each were formed for task and contextual performance. For task performance, one parcel was constructed of three items, with four items constituting the second parcel. For contextual performance, one parcel was formed using the seven items constituting the OCBI sub-dimension of contextual performance, and the other was constructed using the six items representing OCBO. Last, we let the three items pertaining to feedback sought from the supervisor serve as indicators of the latent supervisory feedback construct rather than form a parcel from these items. Parcel formation was identical for the Coworker Feedback Environment (CFE) model; however, the three items tapping coworkers as a source were used for this latent feedback-seeking factor.

\section{The Supervisor Feedback Environment}

The measurement model, which included five latent constructs representing SFE, feedback seeking from supervisors, role clarity, task performance, and contextual performance fit the data well after allowing co-variances between four of the SFE subscale residuals, ${ }^{1}$ $\chi^{2}(92, N=168)=150.55, p<.01$; Comparative Fit Index $(\mathrm{CFI})=.96$; root mean square error 
Table 1

Means, Standard Deviations, and Correlations of All Variables

\begin{tabular}{|c|c|c|c|c|c|c|c|c|c|c|c|c|}
\hline Variable & $M$ & $S D$ & 1 & 2 & 3 & 4 & 5 & 6 & 7 & 8 & 9 & 10 \\
\hline $\begin{array}{l}\text { 1. Supervisor feedback } \\
\text { environment }\end{array}$ & 5.37 & 0.98 & $(.96)$ & & & & & & & & & \\
\hline $\begin{array}{l}\text { 2. Coworker feedback } \\
\text { environment }\end{array}$ & 4.99 & 1.08 & $.44 * *$ & $(.96)$ & & & & & & & & \\
\hline $\begin{array}{l}\text { 3. Supervisor effort } \\
\text { costs }\end{array}$ & 2.33 & 0.90 & $-.27 * *$ & .002 & - & & & & & & & \\
\hline $\begin{array}{l}\text { 4. Coworker effort } \\
\text { costs }\end{array}$ & 2.29 & 0.84 & $-.25 * *$ & $-.31 * *$ & $.43^{* *}$ & - & & & & & & \\
\hline $\begin{array}{l}\text { 5. Supervisor feedback- } \\
\text { seeking behavior }\end{array}$ & 2.98 & 1.18 & $.35^{* *}$ & $.25^{* *}$ & $-.20^{*}$ & $-.18^{*}$ & $(.90)$ & & & & & \\
\hline $\begin{array}{l}\text { 6. Coworker feedback- } \\
\text { seeking behavior }\end{array}$ & 2.23 & 1.17 & $.22 *$ & $.24 * *$ & -.06 & -.13 & $.81 * *$ & $(.87)$ & & & & \\
\hline 7. Role clarity & 5.14 & 1.01 & $.56^{* *}$ & $.23 * *$ & $-.16^{*}$ & -.08 & $.36^{* *}$ & $.34 * *$ & $(.97)$ & & & \\
\hline 8. Task performance & 6.25 & 0.76 & $.21 *$ & $.16^{*}$ & $-.17 *$ & -.01 & $.19 *$ & .13 & $.27 * *$ & $(.82)$ & & \\
\hline $\begin{array}{l}\text { 9. Contextual } \\
\text { performance }\end{array}$ & 5.90 & 0.77 & $.16^{*}$ & 0.11 & .03 & -.03 & $.19^{*}$ & $.29 * *$ & $.17 *$ & $.62 * *$ & $(.89)$ & \\
\hline 10. Tenure & 27.4 & 37.6 & -.11 & -.10 & .03 & .13 & -.05 & -.08 & $.18^{*}$ & .09 & .05 & - \\
\hline
\end{tabular}

Note: Reliabilities are reported in parentheses. Tenure is reported in months. OCBI = Organizational Citizenship Behavior-Individual; OCBO = Organizational Citizenship Behavior-Organization.

$* \mathrm{p}<.05$

$* * \mathrm{p}<.01$ 
Table 2

Fit Indices and Statistics for the a priori, Structural, and Modified Structural Models

\begin{tabular}{|c|c|c|c|c|c|}
\hline & $\chi^{2}$ & $d f$ & CFI & RMSEA & SRMR \\
\hline \multicolumn{6}{|l|}{ Supervisor feedback environment } \\
\hline Measurement model & 150.55 & 92 & .96 & .08 & .06 \\
\hline A priori structural model & 199.97 & 97 & .93 & .09 & .15 \\
\hline Modified structural model (as shown in Figure 1) & 158.41 & 96 & .95 & .08 & .07 \\
\hline $\begin{array}{l}\text { Partial mediation model (added a direct link from } \\
\text { supervisor feedback seeking to task performance) }\end{array}$ & 154.84 & 95 & .95 & .08 & .07 \\
\hline $\begin{array}{l}\text { Partial mediation model (added a direct link from } \\
\text { supervisor feedback seeking to contextual performance) }\end{array}$ & 154.12 & 94 & .95 & .07 & .06 \\
\hline \multicolumn{6}{|l|}{ Coworker feedback environment } \\
\hline Measurement model & 182.51 & 94 & .95 & .07 & .05 \\
\hline A priori structural model (as shown in Figure 2) & 191.98 & 99 & .95 & .07 & .08 \\
\hline $\begin{array}{l}\text { Partial mediation model (added a direct link from } \\
\text { supervisor feedback seeking to task performance) }\end{array}$ & 192.94 & 98 & .95 & .08 & .08 \\
\hline $\begin{array}{l}\text { Partial mediation model (added a direct link from } \\
\text { supervisor feedback seeking to contextual performance) }\end{array}$ & 190.18 & 98 & .95 & .08 & .08 \\
\hline
\end{tabular}

Note: All analyses for the Supervisor Feedback Environment were carried out on $N=168$. All analyses for the Coworker Feedback Environment were carried out on $N=170$. CFI $=$ Comparative Fit Index; SRMR $=$ standardized root mean square residual; RMSEA = root mean square error of approximation.

of approximation $($ RMSEA $)=.08$; standardized root mean residual $($ SRMR $)=.06$ (Table 2). These results provide evidence that the model meets $\mathrm{Hu}$ and Bentler's (1999) conservative two-index presentation criteria for good model fit.

The hypothesized structural model was a mediated model consisting of paths between the SFE, supervisory feedback seeking, role clarity, task performance, and contextual performance, where the supervisor feedback environment was hypothesized to influence feedback seeking and role clarity was hypothesized to fully mediate the relationship between supervisory feedback seeking and task performance, as well as the link between supervisory feed- back seeking and contextual performance. This model fit the data poorly, $\chi^{2}(97, N=168)=199.97, p<.01 ;$ CFI $=.93 ;$ RMSEA $=.09 ;$ SRMR $=.15$, and resulted in a significant decrease in model fit, $\Delta \chi^{2}(5, N=168)=49.42, p<.01$. We then tested a revised model in which we added a direct path, based on modification indices, between the SFE and role clarity (Figure 1). Allowing this path to be freely estimated resulted in a substantial improvement in model fit according to the fit indices, $\chi^{2}(96, \mathrm{~N}$ $=168)=158.41, p<.01 ; \mathrm{CFI}=.95 ;$ RMSEA $=.08 ;$ SRMR $=.07$ (Table 2) and demonstrated a nonsignificant change in fit from the measurement model, $\Delta \chi^{2}(4, N=168)$ $=7.86, p=n s$.

Following this, models were assessed that added a direct path from supervisory feedback seeking to task performance and contextual performance, respectively, to test for the partial mediation of role clarity on these relationships. This first model suggests a partial mediation effect where supervisory feedback seeking operates through and independent of role clarity to influence task performance. This model fit the data well, $\chi^{2}(95, N=168)=154.84, p<.01$; 
$\mathrm{CFI}=.95 ; \mathrm{RMSEA}=.08 ; \mathrm{SRMR}=.07$ (Table 2), and did not fit worse than the measurement model, $\Delta \chi^{2}(3, N=168)=4.29, p=n s$. Compared to the hypothesized model, adding the direct link from supervisory feedback seeking to task performance did not significantly improve model fit, $\Delta \chi^{2}(1, N=168)=3.57, p=n s$. However, inspection of the standardized path coefficients indicated that a direct effect of supervisory feedback seeking on task performance was significant, $p<.05$, indicating that role clarity partially mediated the effects of supervisory feedback seeking on task performance. The second model assessed role clarity as a mediator of the relationship between supervisory feedback seeking and contextual performance. This model also fit the data quite well, $\chi^{2}(94, N=168)=154.12, p$ $<.01 ; \mathrm{CFI}=.95 ; \mathrm{RMSEA}=.07 ; \mathrm{SRMR}=.06$ (Table 2), and did not worsen model fit, $\Delta \chi^{2}(3$, $N=168)=.72, p=n s$. In this case, however, the standardized path coefficient for the supervisor feedback seeking-contextual performance link was nonsignificant, suggesting that role clarity fully mediated the effects of supervisory feedback seeking on contextual performance.

Examination of the paths in the final model demonstrated that Hypothesis 1a was fully supported; perceptions of a supportive SFE positively related to the elicitation of feedback from supervisors. Hypothesis 3a was partially supported as role clarity partially mediated the effects of supervisory feedback seeking on task performance. However, the relationship between feedback seeking from the supervisor and contextual performance was fully mediated by role clarity, supporting Hypothesis 4a.

Hypothesis 2a stated that effort costs would moderate the relationship between the SFE and supervisory feedback seeking. This hypothesis was tested using a hierarchical moderated multiple regression framework (Stone \& Hollenbeck, 1984). We first entered gender, age, and tenure as control variables at Step 1 based on research indicating that these control variables can influence feedback-seeking behavior (Ashford, 1986; Miller \& Karakowsky, 2005). To reduce the possibility of multicollinearity, we mean-centered our independent variables (SFE and supervisory effort costs) and entered these in Step 2 (Aiken \& West, 1991). Finally, we entered the cross-product term, which we calculated as the product of the centered main effect variables. As shown in Table 3, this interaction did not significantly predict supervisory feedback seeking, thus Hypothesis $2 \mathrm{a}$ was not supported.

\section{The Coworker Feedback Environment}

This second model was analyzed in the same manner as the SFE model. The CFE measurement model fit the data well, according to the guidelines set by $\mathrm{Hu}$ and Bentler (1999), $\chi^{2}(94, N=170)=182.51, p<.01 ; \mathrm{CFI}=.95 ; \mathrm{RMSEA}=.07 ; \mathrm{SRMR}=.05$ (Table 2).

Furthermore, the hypothesized structural model (Figure 2) fit the data well, $\chi^{2}(99, N=170)=$ $191.98, p<.01 ; \mathrm{CFI}=.95 ; \mathrm{RMSEA}=.07 ; \mathrm{SRMR}=.08$ (Table 2).

The partial mediation model assessing the mediating effect of role clarity on the relationship between coworker feedback seeking and task performance fit the data well $\chi^{2}(98$, $N=170)=192.94, p<.01 ; \mathrm{CFI}=.95 ; \mathrm{RMSEA}=.08 ; \mathrm{SRMR}=.08$. However, compared to the hypothesized structural model, adding the direct link between coworker feedback seeking and task performance did not significantly improve model fit, $\Delta \chi^{2}(1, N=170)$ $=.96, p=n s$. The standardized coefficient for this relationship was nonsignificant, $p<.05$, further 
indicating that role clarity fully mediated the coworker feedback seeking-task performance link. The second partial mediation model examined the indirect effects of role clarity on the relationship between coworker feedback seeking and contextual performance. Again, model fit was acceptable, $\chi^{2}(98, N=170)=190.18, p<.01 ; \mathrm{CFI}=.95 ; \mathrm{RMSEA}=.08$; SRMR $=$ .08 ; the direct link did not improve model fit, $\Delta \chi^{2}(1, N=170)=1.8, p=n s$; and the standardized coefficient was nonsignificant. These results indicate that role clarity fully mediated the relationship between coworker feedback seeking and contextual performance.

Figure 2 presents the standardized path coefficients for the final CFE model. These results demonstrate support for Hypotheses $1 \mathrm{~b}$; a coworker environment conducive to open feedback seeking was related to feedback seeking from coworkers. Hypotheses $3 b$ and $4 b$ were fully supported as role clarity fully mediated the link between coworker feedback seeking and job performance as well as the relationship between coworker feedback seeking and contextual performance.

Following the procedures outlined above for testing interaction effects (Stone \& Hollenbeck, 1984), we found that the relationship between perceptions of the coworker feedback environment and feedback seeking was moderated by the effort costs associated with seeking feedback from coworkers, thus supporting Hypothesis 2b (Table 3). Using procedures outlined by Aiken and West (1991), the observed coworker interaction was plotted to examine the form of the moderated relationship. Figure 3 illustrates the interaction between perceptions of coworker effort costs and the coworker feedback environment on feedback- seeking behavior for values \pm 1 standard deviation around the mean of the coworker feed- back environment. As expected, there is a positive slope between perceptions of the coworker feedback environment and feedback seeking for those who perceive lower levels of effort costs. Conversely, the slope is flatter for those who perceive higher levels of effort costs associated with obtaining feedback from coworkers.

\section{Supplementary Analyses}

Research within the job performance domain has indicated that although task and contextual performance are conceptually distinct variables, managers integrate task and contextual performance ratings when generating an overall job performance rating (Rotundo \& Sackett, 2002). On the basis of these results, we sought to supplement our focal analyses by combining the separate sub-dimensions of job performance and investigating the effects of feedback seeking and role clarity on a latent multidimensional performance construct.

After making the measurement/structural model modifications outlined above (see Note 1), the final path model for the SFE demonstrated acceptable levels of construct validity, and all standardized path coefficients were significant, $\chi^{2}(84, N=168)=170.82, p<.01 ; \mathrm{CFI}=.95$; $\mathrm{RMSEA}=.07 ; \mathrm{SRMR}=.07$. Furthermore, role clarity fully mediated the relationship between supervisor feedback seeking and job performance. Similarly, the measurement and structural models fit the data quite well for the CFE, $\chi^{2}(87, N=170)=188.14, p<.01$, and demonstrated significant standardized path coefficients. In addition, role clarity fully mediated the link between coworker feedback seeking and job performance for the CFE model as well. 
Table 3

Results of Moderated Regression Analysis for the Supervisor and Coworker Feedback Environment

\begin{tabular}{|c|c|c|c|c|}
\hline Step & Variable & $\beta$ & $R^{2}$ & $\Delta R^{2}$ \\
\hline \multicolumn{5}{|c|}{ Dependent variable $=$ supervisory feedback seeking } \\
\hline \multirow{3}{*}{ Step 1} & Age & -.01 & & \\
\hline & Tenure & .14 & & \\
\hline & Gender & .13 & .04 & \\
\hline \multirow[t]{2}{*}{ Step 2} & SFE & $.19 *$ & & \\
\hline & Effort costs & $-.09 *$ & .10 & $.06^{*}$ \\
\hline Step 3 & SFE $\times$ Effort Costs & -.08 & .11 & .01 \\
\hline \multicolumn{5}{|c|}{ Dependent variable $=$ coworker feedback seeking } \\
\hline \multirow[t]{3}{*}{ Step 1} & Age & -.04 & & \\
\hline & Tenure & .08 & & \\
\hline & Gender & .08 & .01 & \\
\hline \multirow[t]{2}{*}{ Step 2} & CFE & $.18 *$ & & \\
\hline & Effort costs & -.06 & .06 & $.05^{*}$ \\
\hline Step 3 & CFE $\times$ Effort Costs & $-.19 *$ & .10 & $.04 *$ \\
\hline
\end{tabular}

Note: $\mathrm{SFE}=$ supervisor feedback environment; $\mathrm{CFE}=$ supervisor feedback environment. $* p<.05$

Figure 3

Interaction of the Coworker Feedback Environment With Perceived Effort Costs From Coworkers on Feedback-Seeking Behavior From Coworkers

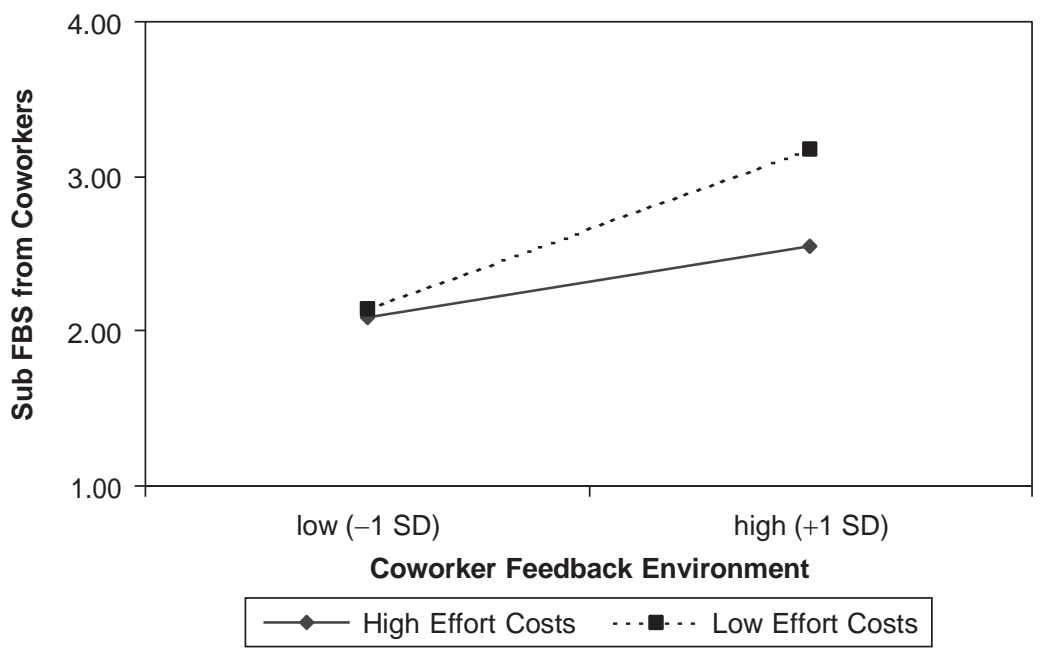




\section{Discussion}

Consistent with our theoretical framework, we found that (a) perceptions of a positive supervisor and coworker feedback environment both led to increased feedback-seeking behavior, (b) perceptions of additional effort costs moderated the relationship between the coworker feedback environment and feedback seeking, and (c) role clarity mediated the relationship between feedback-seeking behaviors and job performance. We also found a strong, unexpected relationship between the supervisor feedback environment and role clarity, which suggests that an open, cooperative feedback policy on the part of supervisors can lead to enhanced employee role clarity independent of active feedback seeking on the part of the employee. Although unexpected, this finding is interesting because it suggests that available, supportive supervisors may serve as salient reminders of the organization that prime employees to become self-aware (Lord \& Brown, 2004) and to focus on known role information. In sum, our findings address several gaps in the literature by exploring the role of contextual antecedents of feedback-seeking behavior (Ashford et al., 2003; Levy \& Williams, 2004; Murphy \& Cleveland, 1995; Steelman et al., 2004) and by explaining how feedback-seeking behavior is tied to job performance through the mediation of role clarity (Ang et al., 1993; Ashford \& Black, 1996; Morrison, 1993).

However, contrary to expectations, we also found that effort costs did not moderate the relationship between the supervisor feedback environment and feedback-seeking behavior from the supervisor as expected in Hypothesis 2a. In contrast, we did find the moderating effect for the coworker feedback environment, implying that effort costs may dissuade feedback seeking from coworkers, but not from supervisors. As Herold and Parsons (1985) noted, coworker feedback is clearly related to job performance, but coworkers do not have formal authority over employees. Their feedback may not be considered as important as the feedback from a supervisor (Kohli \& Jaworski, 1994). The authority of supervisors stems from their provision of performance appraisals that are linked to desirable outcomes, such as pay, in a traditional performance appraisal setting (London, 2003). Coworkers are typically not a part of the performance appraisal process outside of organizations that use team settings (Reilly \& McGourty, 1998) or multisource feedback (Dalessio, 1998). Thus, because supervisory feedback is more closely tied to beneficial outcomes, the perception of effort costs may not discourage feedback seeking from supervisors. In contrast, as rewards are generally not contingent on the feedback of coworkers, high effort costs in seeking feedback from coworkers may lead employees to minimize feedback-seeking behavior, even if the coworker feedback environment is supportive.

Furthermore, Hypothesis 3a was only partially supported because role clarity only partially mediated the link between feedback seeking from the supervisor and task performance. In other words, feedback-seeking behavior had a direct effect on task performance ratings in addition to the indirect effect through increased role clarity. This finding is intriguing as it suggests that supervisors may see feedback-seeking behavior as directly related to task performance. Some evidence supports this perspective. For example, Campbell, Gasser, and Oswald's (1996) taxonomy of performance includes components such as demonstration of effort and maintenance of personal discipline. Supervisors may perceive feedback-seeking 
behavior as consistent with these components because it communicates a desire to maintain performance consistent with organizational standards, and accordingly, they may take feedback-seeking behavior into account when making performance evaluations.

\section{Implications}

These findings have several implications for organizations. First, whereas previous research had found inconsistent effects of feedback seeking on job performance (Ang et al., 1993; Ashford \& Black, 1996; Kluger \& DeNisi, 1996), the results of this study indicate that subordinate feedback seeking does result in positive supervisory evaluations of performance, consistent with the findings of Morrison (1993). Our findings are particularly robust given that performance data were gathered from supervisors who provided their perceptions of employee performance, minimizing biases associated with monosource bias and selfreported data. The mediation of role clarity clearly emphasizes the importance of providing a well-known referent standard of performance to employees, which facilitates the improvement of their performance.

In addition, the moderation of effort costs only on the relationship between the coworker feedback environment and employee feedback seeking has important implications for performance appraisal systems that use coworker input (Dalessio, 1998). Our findings suggest that employees may not be getting feedback even from supportive coworkers if considerable effort is perceived as necessary to do so. Organizations that use coworker feedback in performance appraisal systems should therefore take extra steps to remove barriers and facilitate the exchange of information between coworkers.

Our findings also have important implications for employee development. Encouraging feedback seeking by manipulating the feedback environment should result in enhanced role clarity, consistent with our findings. As Landy and Farr (1980) noted, performance appraisals are conducted in organizations infrequently, oftentimes only once or twice per year (Bernardin, Hagan, Kane, \& Villanova, 1996). Therefore, promoting feedback seeking may serve to encourage employees to seek development-related feedback on a more consistent basis (London, 2003; London \& Smither, 2002), yielding greater role clarity and improvements in performance.

Last, our findings have important implications for the relationship between feedback seeking, role clarity, and contextual performance. Little research has linked role clarity to contextual performance (Podsakoff et al., 1996; Podsakoff et al., 2000), but our findings suggest that feedback-seeking behavior that leads to increased role clarity can facilitate contextual performance. Specifically, our results imply that feedback-seeking behavior provides employees with an enhanced understanding of the types of contextual performance that are valued by the organization, as well as with a firmer insight into when and how OCBs can be performed without detracting from necessary task performance. Thus, role clarity may contribute to organizational effectiveness not only by improving task performance but also by increasing the ability of employees to engage in contextual performance. 


\section{Limitations and Future Research}

Although our findings have helped to answer several recent calls in the feedback-seeking literature, our study did have several limitations. For example, one limitation of this study was our use of a student sample, which limits generalizability. Although our sample was composed of older student employees with more work experience than traditional college students, use of this sample may have nevertheless restricted the range on relevant variables such as demographic characteristics (i.e., gender) as well as job-related variables (i.e., hours worked per week, tenure). For example, our sample was almost three quarters female, working on average 26.5 hours per week, with an average tenure of 2 years and 3 months. Thus, if any of the constructs under study are preferentially affected by gender or require a significant amount of time on the job to form associations, our findings may be artificially enhanced or attenuated. Future researchers should attempt to replicate our results on older, full-time employees with more experience in the workforce to ensure the generalizability of our findings.

We also wish to emphasize that our hypothesis testing was conducted in a cross-sectional manner, which limits the extent that causality can be assessed. In particular, future research should focus on identifying the antecedents that contribute to the formation of a supportive feedback environment, which have received little research attention to date. Determining these antecedents would make it easier for researchers to design longitudinal studies that focus on the processes shown in our models. Eventually, interventions may be implemented designed to improve the feedback environment, resulting in more feedback seeking, role clarity, affective commitment (Norris-Watts \& Levy, 2004), employee morale (Rosen, et al., 2006), and both task and contextual performance.

Another limitation involves the scope of the antecedents of feedback-seeking behavior that we considered. Our focus was on contextual antecedents of feedback seeking, such as the feedback environment, rather than individual differences. A wide body of literature has shown that individual differences such as impression management, self-esteem, and goal orientation influence feedback-seeking behavior as well (e.g., Levy et al., 1995; VandeWalle, 2003), and future research should look at the interactions of these individual and contextual variables. For example, Levy et al. (1995) demonstrated that public contexts and individual differences such as social anxiety and public self-consciousness interacted to influence feedback-seeking behavior.

Last, because of limitations in the only existing scale of effort costs (Ashford \& Cummings, 1983), we measured subordinate perceptions of the effort costs required to seek feedback from the supervisor and coworkers using single-item scales. The decision to use single-item measures introduces problems with measurement reliability, raises questions regarding the extent to which we have measured the relevant construct domain, and may lead to spurious associations among the variables under study (Spector, 1992). As outlined by Sackett and Larson (1990), a single-item measure is most appropriately used in situations in which the construct of interest is sufficiently narrow in scope, unidimensional rather than multidimensional, and the item is clear to the respondents. Thus, to the extent that perceptions of supervisor and coworker effort costs are narrow and unidimensional, and the items themselves are readily interpretable by the respondents, single-item measures may suffice. 
However, very little theoretical or empirical work has been carried out investigating the breadth of the effort costs construct. Future research adopting the construct of effort costs should elaborate on our findings by developing and employing a more extensive measure of effort costs to ensure adequate domain coverage.

\section{Conclusion}

Our findings have emphasized the importance of the feedback environment in organizations that seek to improve feedback-seeking behaviors. We have demonstrated that perceptions of a supportive feedback environment encourage feedback-seeking behavior, but that this relationship is moderated by effort costs for feedback seeking from coworkers. We have also shown that feedback seeking is related to task and contextual performance through the mediator of role clarity. Overall, this model provides new directions for research on feed- back. Moreover, it generates useful implications for both researchers and practitioners to increase job performance through a consideration of the feedback environment, employees' perceptions of their roles, and the costs associated with clarifying them.

\section{Note}

1. In two instances, we allowed residuals to covary. Error variances were allowed to intercorrelate for the items referring to the promotion of feedback seeking and source availability. Similarly, we allowed the error variances for the items pertaining to feedback frequency and source credibility to covary.

\section{References}

Aiken, L. S., \& West, S. G. 1991. Multiple regression: Testing and interpreting interactions. Newbury Park, CA: Sage.

Ang, S., Cummings, L., Straub, D., \& Early, P. 1993. The effects of information technology and the perceived mood of the feedback giver on feedback seeking. Information Systems Research, 4: 240-261.

Ashford, S. 1986. Feedback-seeking in individual adaptation: A resource perspective. Academy of Management Journal, 29: 465-487.

Ashford, S. 1988. Individual strategies for coping with stress during organizational transitions. Journal of Applied Behavioral Science, 24: 19-36.

Ashford, S. \& Black, J. 1996. Proactivity during organizational entry: The role of desire for control. Journal of Applied Psychology, 81: 199-214.

Ashford, S., Blatt, R., \& VandeWalle, D. 2003. Reflections on the looking glass: A review of research on feedback- seeking behavior in organizations. Journal of Management, 29: 773-799.

Ashford, S., \& Cummings, L. 1983. Feedback as an individual resource: Personal strategies of creating information. Organizational Behavior and Human Performance, 32: 370-398.

Ashford, S., \& Cummings, L. 1985. Proactive feedback seeking: The instrumental use of the information environment. Journal of Occupational Psychology, 58: 57-79.

Banton, M. 1965. Roles: An introduction to the study of social relations. New York: Basic Books.

Bernardin, H. J., Hagan, C., Kane, J., \& Villanova, P. 1996. Effective performance management: A focus on precision, customers, and situational constraints. In J. W. Smither (Ed.), Performance appraisal: State of the art in practice: 3-48. San Francisco, CA: Jossey-Bass. 
Bolino, M., \& Turnley, W. 2005. The personal costs of citizenship behavior: The relationship between individual initiative and role overload, job stress, and work-family conflict. Journal of Applied Psychology, 90: 740-748.

Bond, J., Galinksy, E., \& Swanberg, G. 1997. The 1997 national study of the changing workforce. New York: Families and Work Institute.

Borman, W. C., \& Motowidlo, S. J. 1993. Expanding the criterion domain to include elements of contextual performance. In N. Schmitt \& W. C. Borman (Eds.), Personnel selection in organizations: 71-98. San Francisco: Jossey-Bass.

Callister, R., Kramer, M., \& Turban, D. 1999. Feedback seeking following career transitions. Academy of Management Journal, 42: 429-438.

Campbell, J., Gasser, M., \& Oswald, F. 1996. The substantive nature of job performance variability. In K. R. Murphy (Ed.), Individual differences and behavior in organizations: 258-299). San Francisco: Jossey-Bass.

Dalessio, A. T. 1998. Using multisource feedback for employee development and personnel decisions. In J. W. Smither (Ed.), Performance appraisal: State of the art in practice: 278-330. San Francisco: Jossey-Bass.

Fedor, D., Rensvold, R., \& Adams, S. 1992. An investigation of factors expected to affect feedback seeking: A longitudinal field study. Personnel Psychology, 45: 779-805.

Fried, Y., Ben-David, H., Tiegs, R., Avital, N., \& Yeverechyahu, U. 1998. The interactive effect of role conflict and role ambiguity on job performance. Journal of Occupational \& Organizational Psychology, 71: 19-27.

Hackman, J., \& Oldham, G. 1976. Motivation through the design of work: Test of a theory. Journal of Vocational Behavior, 31: 278-296.

Hall, R. J., Snell, A. F., \& Foust, M. S. 1999. Item parceling strategies in SEM: Investigating the subtle effects of unmodeled secondary constructs. Organizational Research Methods, 2: 233-256.

Herold, D., \& Parsons, C. 1985. Assessing the feedback environment in work organizations: Development of the job feedback survey. Journal of Applied Psychology, 70: 290-305.

Hu, L., \& Bentler, P. 1999. Cutoff criteria for fit indexes in covariance structure analysis: Conventional criteria versus new alternatives. Structural Equation Modeling, 6: 1-55.

Ilgen, C., Fisher, T., \& Taylor, M. 1979. Consequences of individual feedback on behavior in organizations. Journal of Applied Psychology, 64: 349-371.

Kahn, R. L., Wolfe, D. M., Quinn, R. P., Snoek, J. D., \& Rosenthal, R. A. 1964. Organizational Stress: Studies in role conflict and ambiguity. New York: John Wiley.

Karan, B., \& Kopelman, R. 1986. The effects of objective feedback on vehicular and industrial accidents: A field experiment using outcome feedback. Journal of Organizational Behavior Management, 8: 45-56.

Kluger, A., \& DeNisi, A. 1996. Effects of feedback intervention on performance: A historical review, a metaanalysis, and a preliminary feedback intervention theory. Psychological Bulletin, 119: 254-284.

Kohli, A. K., \& Jaworski, B. J. 1994. The influence of coworker feedback on salespeople. Journal of Marketing, 58: 82-94.

Landy, F., \& Farr, J. 1980. Performance rating. Psychological Bulletin, 87: 72-107.

Levy, P., Albright, M., Cawley, B., \& Williams, J. 1995. Situational and individual determinants of feedback seeking: A closer look at the process. Organizational Behavior \& Human Decision Processes, 62: 23-34.

Levy, P., \& Williams, J. 1998. The role of perceived system knowledge in predicting appraisal reactions, job satisfaction, and organizational commitment. Journal of Organizational Behavior, 19: 53-65.

Levy, P. E., \& Williams, J. R. 2004. The social context of performance appraisal: A review and framework for the future. Journal of Management, 30: 881-905.

London, M. 2003. Job feedback: Giving, seeking and using feedback for performance improvement (2nd ed.). Mahwah, NJ: Lawrence Erlbaum.

London, M., \& Smither, J. 2002. Can working with an executive coach improve multisource feedback ratings over time? A quasi-experimental field study. Personnel Psychology, 56: 23-46.

Lord, R. G., \& Brown, D. J. 2004. Leadership processes and follower self-identity. Mahwah, NJ: Lawrence Erlbaum.

McEnrue, M. 1984. Perceived competence as a moderator of the relationship between role clarity and job performance: A test of two hypotheses. Organizational Behavior \& Human Decision Processes, 34: 374-386.

Mignerey, J., Rubin, R., \& Gorden, W. 1995. Organizational entry: An investigation of newcomer communication behavior and uncertainty. Communication Research, 22: 54-85. 
Miller, D. L., \& Karakowsky, L. 2005. Gender influences as an impediment to knowledge sharing. Journal of Psychology: Interdisciplinary and Applied, 139(2): 101-118.

Morrison, E. 1993. Longitudinal study of the effects of information seeking on newcomer socialization. Journal of Applied Psychology, 78: 173-183.

Morrison, E. 2002. Newcomers' relationships: The role of social network ties during socialization. Academy of Management Journal, 45: 1149-1160.

Morrison, E., \& Bies, R. 1991. Impression management in the feedback-seeking process: A literature review and research agenda. Academy of Management Review, 16: 522-541.

Morrison, E., \& Vancouver, J. 2000. Within-person analysis of information seeking: The effects of perceived costs and benefits. Journal of Management, 26: 119-137.

Murphy, K., \& Cleveland, J. 1995. Understanding performance appraisal: Social, organizational, and goal-based perspectives. Thousand Oaks, CA: Sage Publications.

Nhundu, T. 1992. Job performance, role clarity, and satisfaction among teacher interns in the Edmonton Public School System. Alberta Journal of Educational Research, 38: 335-354.

Norris-Watts, C., \& Levy, P. 2004. The mediating role of affective commitment in the relation of the feedback environment to work outcomes. Journal of Vocational Behavior, 65: 351-365.

Podsakoff, P., MacKenzie, S., \& Bommer, W. 1996. Meta-analysis of the relationships between Kerr and Jermier's substitutes for leadership and employee job attitudes, role perceptions, and performance. Journal of Applied Psychology, 81: 380-399.

Podsakoff, P., MacKenzie, S., Paine, J., \& Bachrach, D. 2000. Organizational citizenship behaviors: A critical review of the theoretical and empirical literature and suggestions for future research. Journal of Management, 26: 513-563.

Reilly, R. R., \& McGourty, J. 1998. Performance appraisal in team settings. In J. W. Smither (Ed.), Performance appraisal: State of the art in practice: 278-330. San Francisco: Jossey-Bass.

Renn, R. W., \& Fedor, D. B. 2001. Development and field test of a feedback seeking, self-efficacy, and goal setting model of work performance. Journal of Management, 27: 563-583.

Rosen, C., Levy, P., \& Hall, R. 2006. Placing perceptions of politics in the context of the feedback environment, employee attitudes, and job performance. Journal of Applied Psychology, 91: 211-220.

Rotundo, M., \& Sackett, P. 2002. The relative importance of task, citizenship, and counterproductive performance to global ratings of job performance: A policy-capturing approach. Journal of Applied Psychology, 87: 66-80.

Sackett, P., \& Larson, J. 1990. Research strategies and tactics in industrial and organizational psychology. In M. D. Dunnette \& L. M. Hough (Eds.), Handbook of industrial and organizational psychology, 2nd ed., Vol. 1: 419-489. Palo Alto, CA: Consulting Psychologists.

Salamon, S., \& Deutsch, Y. 2006. OCB as a handicap: An evolutionary psychological perspective. Journal of Organizational Behavior, 27: 185-199.

Sawyer, J. 1992. Goal and process clarity: Specification of multiple constructs of role ambiguity and a structural equation model of their antecedents and consequences. Journal of Applied Psychology, 77: 130-142.

Spector, P. 1992. Summated rating scale construction: An introduction. Newbury Park, CA: Sage.

Steelman, L., Levy, P., \& Snell, A. F. 2004. The feedback environment scale (FES): Construct definition, measurement, and validation. Education and Psychological Measurement, 64: 165-184.

Steelman, L., \& Rutkowski, K. 2004. Moderators of employee reactions to negative feedback. Journal of Managerial Psychology, 19: 6-18.

Stone, E., \& Hollenbeck, J. 1984. Some issues associated with the use of moderated regression. Organizational Behavior \& Human Decision Processes, 34: 194-213.

Taylor, M., Fisher, C., \& Ilgen, D. 1984. Individuals' reactions to performance feedback in organizations: A control theory perspective. In K. Rowland \& J. Ferris (Eds.), Research in Personnel and Human Resource Management, Vol. 2: 91-124. Greenwich, CT: JAI.

Tuckey, M., Brewer, N., \& Williamson, P. 2002. The influence of motives and goal orientation on feedback seeking. Journal of Occupational \& Organizational Psychology, 75: 195-216.

VandeWalle, D. 2003. A goal orientation model of feedback-seeking behavior. Human Resource Management Review, 13: 581-604.

VandeWalle, D., \& Cummings, L. 1997. A test of the influence of goal orientation on the feedback seeking process. Journal of Applied Psychology, 82: 390-400. 
VandeWalle, D., Ganesan, S., Challagalla, G., \& Brown, S. 2000. An integrated model of feedback-seeking behavior: Disposition, context, and cognition. Journal of Applied Psychology, 85: 996-1003.

Wanberg, C., \& Kammeyer-Mueller, J. 2000. Predictors and outcomes of proactivity in the socialization process. Journal of Applied Psychology, 85: 373-385.

Williams, J., \& Johnson, M. 2000. Self-supervisor agreement: The influence of feedback seeking on the relationship between self and supervisor ratings of performance. Journal of Applied Social Psychology, 30: $275-292$.

Williams, J., Miller, C., Steelman, L., \& Levy, P. 1999. Increasing feedback seeking in public contexts: It takes two (or more) to tango. Journal of Applied Psychology, 84: 969-976.

Williams, L., \& Anderson, S. 1991. Job satisfaction and organizational commitment as predictors of organizational citizenship and in-role behaviors. Journal of Management, 17: 601-617.

Wiliams, L. J., \& Anderson, S. E. 1994. An alternative approach to method effects by using latent-variable models: Applications in organizational behavior research. Journal of Applied Psychology, 79: 323-331.

\section{Biographical Notes}

Brian G. Whitaker is a PhD candidate in the University of Akron's Industrial/Organization Psychology Department. He received his BA from the University of Louisville and his MA in industrial/organizational psychology from Xavier University. His research interests include performance appraisal, feedback seeking, Machiavellianism in the workplace, and measurement issues.

Jason J. Dahling is a doctoral student at the University of Akron. His educational background includes a BA degree from Virginia Tech and a MA in industrial/organizational psychology from the University of Akron. His research interests include feedback seeking within organizations, Machiavellianism and counterproductive work behaviors, and emotional labor.

Paul E. Levy, PhD, is a professor and chair of the Department of Psychology at the University of Akron and former chair of the Industrial/Organizational program. He received his $\mathrm{PhD}$ in industrial/organizational psychology from Virginia Tech in 1989. His consulting and research interests include performance appraisal, feedback, motivation, organizational justice, and coaching. 